\title{
First report of Peronospora saturejae-hortensis in Iran
}

\author{
Hadi Khateri ${ }^{1} @ \cdot$ Nahid Moarrefzadeh ${ }^{1} \cdot$ Samad Jamali $^{1}$
}

Received: 11 June 2020 / Accepted: 20 December 2020 / Published online: 6 February 2021

(c) Australasian Plant Pathology Society Inc. 2021

\begin{abstract}
In November 2018 severe downy mildew infection was observed on summer savory plants in Kermanshah Province, Iran. Leaves on infected plants displayed chlorosis-browning on the upper surfaces and abundant dark gray-brown sporulation of the asexual morph on the lower surfaces. Based on the morphological characteristics and molecular analyses using ITS-1 and ITS-4, the species was identified as Peronospora saturejae-hortensis. The nucleotide sequence of this pathogen had a very high (99.9\%) identity with a previously reported sequence of $P$. saturejae-hortensis from Germany. The possibility of infection on other native Satureja species in Iran is discussed.
\end{abstract}

Keywords Aromatic plants $\cdot$ Lamiaceae $\cdot$ ITS $\cdot$ rDNA $\cdot$ Peronosporales

Summer savory (Satureja hortensis) is an important aromatic plant in the Lamiaceae family. It is being used as a fresh vegetable, food additive and in many medicinal applications (Hassanzadeh et al. 2016; Mozaffarian 2013).

In November 2018 severe downy mildew infection was observed on approximately $70 \%$ of summer savory plants growing in experimental plots inside a research greenhouse at the College of Agriculture, Razi University (Kermanshah, Iran). This greenhouse had high humidity conditions and the temperatures inside were between $18-25{ }^{\circ} \mathrm{C}$. Leaves on infected plants were chlorotic-brown on the upper surface (Fig. 1a) and there was a dark gray-brown sporulation consisting of conidiophores bearing conidia which covered the entire lower surface (Fig. 1b). Later, most infected leaves died. A voucher specimen of diseased material (designated as Felfelak1) was deposited with the herbarium number RUHK-2903 in Razi University Herbarium, (Kermanshah, Iran).

The fungal mass (comprising the asexual morph) was scraped from the lower leaf surfaces and mounted in water or lactophenol-cotton blue on microscope slides. Slides were examined and photographed using an Olympus $\mathrm{CH} 40$ microscope equipped with a JVC color video camera (model TK-C1480E). Measurements of conidia and conidiophores

Hadi Khateri

hkhateri@ razi.ac.ir

1 Department of Plant Protection, College of Agriculture, Razi University, Kermanshah, Iran
(30 for each) were done by BioloMICS software (Version 1.0.2, BioAware) and are reported as follows, (minimum-) $\mathrm{y}-\mathrm{z}$ (-maximum), where $\mathrm{y}=$ mean-standard deviation and $\mathrm{z}=$ mean + standard deviation. All the values were rounded to the nearest whole number. The conidiophores were (190-)345-585(-610) $\mu \mathrm{m}$ in length and had four to five branches (Fig. 1c). The lengths of the longer and the shorter ultimate branchlets (Fig. 1d) were (7-)9-18(-22) $\mu \mathrm{m}$ and (4-)4-7(-8) $\mu \mathrm{m}$, respectively. Obovoid, brown-olive conidia (17-)17-23(-25) $\mu \mathrm{m} \times(12-) 13-18(-21) \mu \mathrm{m}$, length/width ratio 1.1-1.7, developed singly at the tips of the ultimate branchlets (Fig. 1e). Conidia germinated by producing a single unbranched germ tube. No oospore was found in the examined samples.

The species had morphological characteristics very similar to those of Peronospora saturejae-hortensis (Gabler et al. 2012). The dimensions of conidia were similar to those reported by Gabler et al. (2012), i.e. (15-)16-25 $(-26) \times(9-) 10-18(-19)$, but were larger than the dimensions published in the original description (Novotelnova and Pystina 1985), i.e. $14.5-18 \times 12-15 \mu \mathrm{m}$. The reason for this difference with the latter could be due to the influence of the environment, differences in host matrix (Runge et al. 2012) and that the species author had not examined fresh, fully developed material (Gabler et al. 2012).

Pathogenicity testing was conducted as described by Gabler et al. (2012). The inoculum was prepared from the same infected samples that were used for morphological and molecular studies by stirring $150 \mathrm{~g}$ infected leaves in 
Fig. 1 Symptoms, signs and microscopic images of downy mildew caused by Peronospora saturejae-hortensis on summer savory; a browning of upper leaf surfaces on infected plants, b sporulation of the asexual morph on the lower leaf surfaces, c conidiophore (bar $=100 \mu \mathrm{m}), \mathbf{d}$ ultimate branchlets $(\mathrm{bar}=20 \mu \mathrm{m})$, e conidia $($ bar $=10 \mu \mathrm{m})$
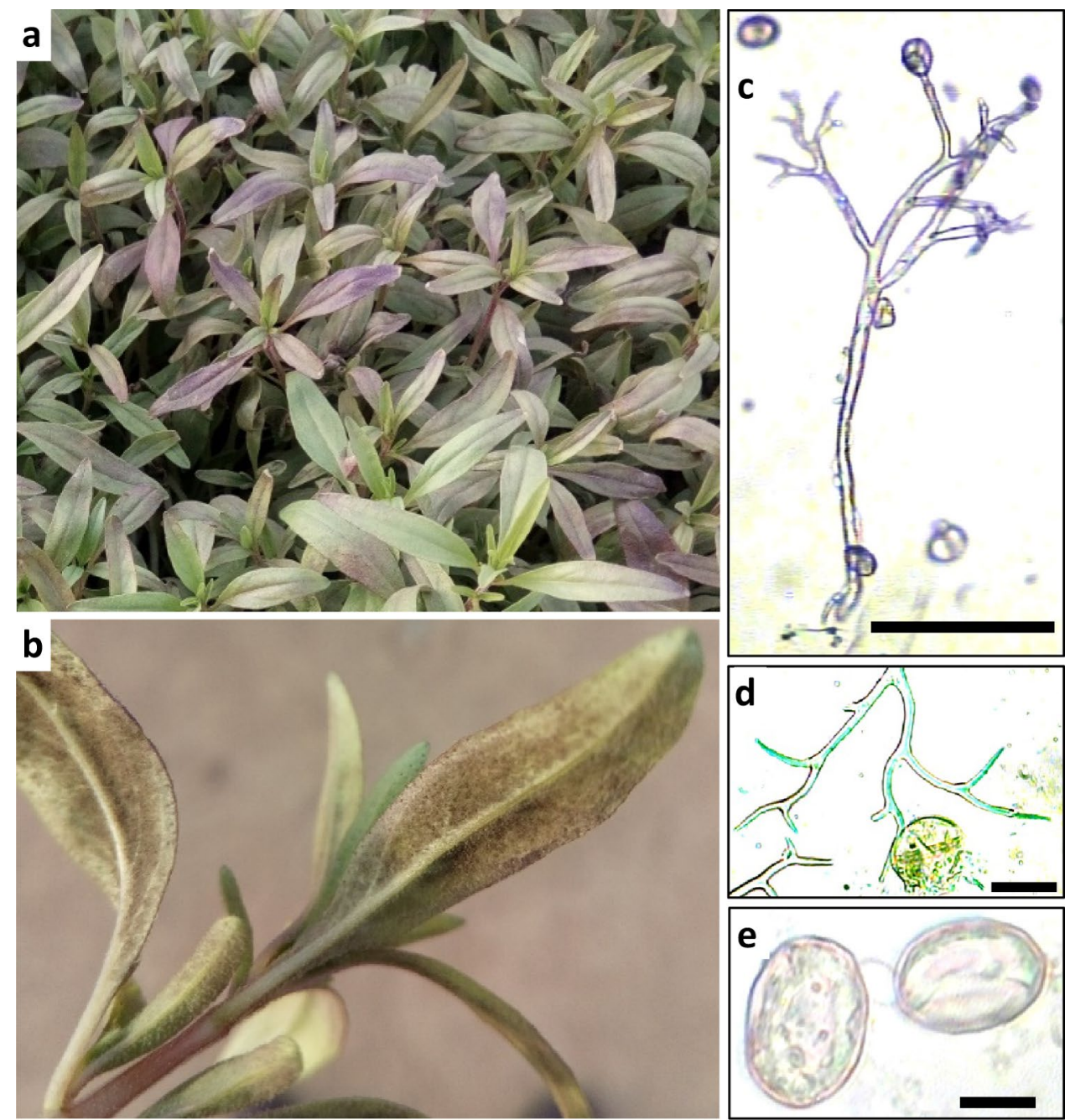

$400 \mathrm{ml}$ water with the addition of $30 \mu \mathrm{l}$ Tween 20 . The suspension was adjusted to approximately $1 \times 10^{6}$ conidia/ $\mathrm{ml}$. Inoculation was done by submerging the eight weeks old summer savory plants in the aqueous suspension of conidia for about $30 \mathrm{~s}$. The inoculated plants were then covered for the entire period of the experiment in a moistened plastic bag starting immediately after inoculation and incubated in a greenhouse at $18-24{ }^{\circ} \mathrm{C}$. The first symptoms appeared after 12 days as small yellow spots on the upper leaf surfaces and after 20 days sporulation consisting of conidiophores and conidia identical to those of $P$. saturejae-hortensis occurred on the abaxial surfaces of the spots. Microscopic examination of the conidiophores and conidia on the inoculated plants confirmed that it was consistent with P. saturejae-hortensis.

A spore suspension was collected by spraying the lower leaf surfaces of a downy mildew infected summer savory sample by a hand-held water sprayer and after centrifugation was stored at $-20{ }^{\circ} \mathrm{C}$ for DNA extaction. DNA was extracted using a commercial kit (Zagros Bioidea Co., Razi University Incubator, Kermanshah, Iran). PCR was done by using primers
ITS1 and ITS4 (White et al. 1990). The PCR product was sequenced by a commercial service (Pishgam Biotech Co., Tehran, Iran) and the sequence was deposited in GenBank under accession number MT510002. BLAST analysis revealed a very high $(99.9 \%)$ nucleotide identity (the only difference was an ambiguous nucleotide) with the ITS and ribosomal RNA sequence of $P$. saturejae-hortensis previously reported from Germany under the GenBank accession number JN882274 (Gabler et al. 2012). The phylogenetic tree (not shown) that was reconstructed by the same method and the same set of sequences used by Gabler et al. (2012), was similar to that report and the Iranian isolate was in the same clade as the the German isolate that was characterised by Gabler et al. (2012). Except for these two accession numbers (JN882274 and MT510002), there is currently no other available sequences from the ITS and ribosomal RNA genes of this species. The almost identical nucleotide sequences from these two accession numbers reveal a very high genetic conservation in this region and a potentially identical source for both occurrences. Based on both morphological and 
molecular characterisation, the Iranian isolate RUHK-2903 can be considered to be $P$. saturejae-hortensis.

Although many Peronospora species show a high degree of host specialization (Spring et al. 2019; Thines and Choi 2016), there are also some species including Peronospora belbahrii (Ben-Naim et al. 2019; Cohen et al. 2017) and Peronospora tabacina (Hall 1989; Kröber and Massfeller 1961) that infect multiple plant species and genera. More than 16 species of Satureja such as Satureja kermanshahensis and Satureja khuzistanica (Jamzad 2010) grow naturally as annual or perennial plants in Iran (Mozaffarian 2013) and there is a possibility that $P$. saturejae-hortensis also causes a similar disease on one or more of these species which may act as inoculum sources and overwintering hosts. Another possible source of inoculum for the infection of summer savory plants that needs to be studied in future is infected seed which has been documented in the case of P. belbahrii, the causal agent of basil downy mildew (Garibaldi et al. 2004; Wyenandt et al. 2015).

P. saturejae-hortensis has been reported as the causal agent of downy mildew on summer savory from Germany and Armenia (Gabler et al. 2012; Novotelnova and Pystina 1985), whilst the causal agent of downy mildew on summer savory in Bulgaria and Lithuania has been recorded as $P$. calaminthae (Gabler et al. 2012). The only published report of Peronospora on summer savory in Iran was that of Peronospora lamii from Khuzestan Province in the southwest of the country (Ershad 1977). Except for this report and others on the occurrence of downy mildew on basil in the south-west (Ebrahimi and Minassian 1973), north (Khateri et al. 2007) and west (Khateri et al. 2019) of Iran, there was no information about the downy mildews on plants in the Lamiaceae in other parts of the country. Previous studies have identified many Peronospora collections from different Lamiaceae plants as $P$. lamii which is due to the application of a morphologically-based broad species concept (Gabler et al. 2012). This assumption may have been the reason for neglecting the possible preventive measures such as seed tests (Thines and Choi 2016). The molecular analysis by nucleotide sequences helps to override such problems and differentiate the nearly related but different species such as P. lamii, P. belbahrii and P. saturejae-hortensis (Gabler et al. 2012).

\section{References}

Ben-Naim Y, Falach-Block L, Ben-Daniel B-H, Cohen Y (2019) Host range of Peronospora belbahrii, causal agent of basil downy mildew, in Israel. Eur J Plant Pathol 155:789-799. https://doi. org/10.1007/s10658-019-01809-9
Cohen Y, Ben-Naim Y, Falach L, Rubin AE (2017) Epidemiology of basil downy mildew. Phytopathology 107:1149-1160. https://doi. org/10.1094/PHYTO-01-17-0017-FI

Ebrahimi A, Minassian V (1973) An index of cultivated and wild plant diseases in Khuzestan. Jundi-shapour University, College of Agriculture, Ahvaz, Iran

Ershad D (1977) Fungi of Iran. Plant Pests and Diseases Research Institute (Iran), Department of Botany, Publication No. 10, Tehran, Iran

Gabler J, Hagedorn G, Braun U (2012) Taxonomy and phylogenetic placement of the downy mildew Peronospora saturejae-hortensis. Mycotaxon 121:455-463. https://doi.org/10.5248/121.455

Garibaldi A, Minuto A, Minuto G, Bertetti D, Gullino M (2004) The downy mildew of sweet basil: seed transmission and disease control. J Plant Pathol 86:320-321

Hall G (1989) Peronospora hyoscyami f. sp. tabacina, CMI Descriptions of Pathogenic Fungi and Bacteria No. 975. Mycopathologia 106:191-193

Hassanzadeh MK, Tayarani Najaran Z, Nasery M, Emami SA (2016) Summer Savory (Satureja hortensis L.) Oils. In: Preedy VR (ed) Essential Oils in Food Preservation, Flavor and Safety. Academic Press, San Diego, pp 757-764. https://doi.org/10.1016/B978-012-416641-7.00086-9

Jamzad Z (2010) A new species of Satureja (Lamiaceae) from Iran. Iran J Bot 16:213-217

Khateri H, Calmin G, Moarrefzadeh N, Belbahri L, Lefort F (2007) First report of downy mildew caused by Peronospora sp. on basil (Ocimum basilicum) in northern Iran. J Plant Pathol 89:S70

Khateri H, Moarrefzadeh N, Jamali S (2019) The first report of Peronospora belbahrii the causal agent of downy mildew on sweet basil in the west of Iran. Paper presented at the First Iranian Phytopathology Congress, Karaj, Iran, 31 Aug-1 Sep 2019

Kröber H, Massfeller D (1961) Untersuchungen über die blauschimmelkrankheit des tabaks in Deutschland, IV. Das wirtsspektrum von Peronospora tabacina Adam. Nachrichtenblatt des Deutschen Pflanzenschutzdienstes 13:81-85

Mozaffarian V (2013) Identification of Medicinal and Aromatic Plants of Iran. Farhange-Moaser Publishing, Tehran, Iran

Novotelnova N, Pystina K (1985) Flora Plantarum Cryptogamarum URSS, Vol XI Fungi (3) Ordo Peronosporales (Fam. Pythiaceae, Phytophthoraceae, Peronosporaceae, Cystopaceae). Nauka Press, Leningrad (In Russian)

Runge F, Ndambi B, Thines M (2012) Which morphological characteristics are most influenced by the host matrix in downy mildews? A case study in Pseudoperonospora cubensis. PLoS ONE 7:e44863. https://doi.org/10.1371/journal.pone.0044863

Spring O, Gomez-Zeledon J, Hadziabdic D, Trigiano RN, Thines M, Lebeda A (2019) Biological characteristics and assessment of virulence diversity in pathosystems of economically important biotrophic oomycetes. Crit Rev Plant Sci 37:439-495. https://doi. org/10.1080/07352689.2018.1530848

Thines M, Choi YJ (2016) Evolution, diversity, and taxonomy of the Peronosporaceae, with focus on the genus Peronospora. Phytopathology 106:6-18. https://doi.org/10.1094/PHYTO05-15-0127-RVW

White TJ, Bruns T, Lee S, Taylor J (1990) Amplification and direct sequencing of fungal ribosomal RNA genes for phylogenetics. In: Innis MA, Gelfand DH, Sninsky JJ, White TJ (eds) PCR Protocols: A Guide to Methods and Applications. Academic Press, San Diego, CA, pp 315-322

Wyenandt CA et al (2015) Basil downy mildew (Peronospora belbahrii): discoveries and challenges relative to its control. Phytopathology 105:885-894. https://doi.org/10.1094/PHYTO02-15-0032-FI 